\title{
Analysis on Effect of Public Expenditure in Incentive to Enterprises' Innovation Independently in Inner Mongolia
}

\author{
Peixiao Qi (Corresponding author) \\ Department of Economics, Management College, Inner Mongolia University of Technology \\ 49 Aimin Road, Xincheng District, Huhhot 010051, Inner Mongolia, China \\ Tel: +86-159-4721-0861 E-mail: qipeixiao@foxmail.com \\ Associate Prof. Xiaoyan Hao \\ Management College, Inner Mongolia University of Technology \\ 49 Aimin Road, Xincheng District, Huhhot 010051, Inner Mongolia, China \\ Tel: +86-136-9471-2449 E-mail: haoxiaoyanyan@163.com \\ Jianwen Shi \\ Management College, Inner Mongolia University of Technology \\ 49 Aimin Road, Xincheng District, Huhhot 010051, Inner Mongolia, China \\ Tel: +86-158-4817-8428Ｅ-mail: shijianwen622@163.com
}

Received: October 22, $2010 \quad$ Accepted: November 3, $2010 \quad$ doi:10.5430/jms.v1n1p33

The research is financed by Natural Science Fund Project of Inner Mongolia. No. 2009 MS1009 (person in charge: Xiaoyan Hao) and Scientific Research Project of Institutions of Higher Education in Inner Mongolia. No. NJ09074 (person in charge: Xiaoyan Hao).

\begin{abstract}
In recent years, the Ministry of Finance in China has successively formulated some fiscal policies and measures to stimulate technological innovation. With the scale of public expenditure increasing, government and the academic commonly focus on the issue that result of incentive to innovation. This paper firstly conducts an empirical test by using empirical data of Inner Mongolia Autonomous Region in order to find the relationship between public expenditure and innovation independently. Secondly the author estimates the optimal scale of R\&D expenditure. Finally, the author proposes corresponding policy-suggestions according to the calculate results.
\end{abstract}

Keywords: Public expenditure, Innovation independently, Granger causality test

\section{Introduction}

"Incentive" is originally from an English word: Motivation. For enterprises, the so-called incentive mechanism is essentially a kind of mechanism to meet multiple needs of employees, its purpose is to make private targets of employees consistent with employers' targets and maximize managers' targets (Wang Yunfang, Yue Ying, 2008). Schumpeter had given specifically the definition of innovation in Theory of Economic Development (German Edition, 1912) for the first time (Liu Qiongzhi, 2009). He thought innovation is to lead a new combination of factors of production never before into production system for potential profit. After Schumpeter, innovation theory has aroused people's widespread interest to study it.

Since reform and opening-up, China's economic construction has made great achievements, but two questions need to strive to resolve:

-First, the rapid growth of China's economy mainly depends on high input and consumption of resources.

-Second, because of over-attention to introduction and ignoring digestion \& absorption and innovation for a long time, this phenomenon has led to continuously repeated introduction and more dependence on foreign technology. 
At present, the contribution of scientific and technological progress to China's economic growth is only $39 \%$, but $70 \%$ in other innovation-oriented countries. The enterprises which possess independent intellectual property technology are only $0.3 \%$, the index enterprises depend on foreign technology is $50 \%$, however, below $30 \%$ in other innovation-oriented countries and only around 5\% in USA and Japan (Wang Yunfang \&Yue Ying, 2008).

\section{Review of literature}

Nelson and Winter (1982) found that innovation has public-goods property and innovation activities have significantly positive externalities, which means that government intervention is necessary. Innovation capital has also public-goods property, once knowledge is created, most for free, which absolutely bring great incentive to "free ride", so government intervention is also necessary. Delong and Summers (1991) provided relevant evidence. They pointed out that the rate of social return from innovation investment exceeds the rate of private return in a perfect market economy. Nadiri's result was that the rate of social return is $50 \%$, but $20 \%-30 \%$ for the rate of private return (Nadiri, 1993).

Cropper and Oates (1992) proposed five major public policies to correct externalities:

(1) Tax.

(2) Public expenditure.

(3) Creating markets.

(4) Establishing property.

(5) Regulation.

These five policies have different scope and objects when they are applied. Rosen (1995) thought tax mainly corrects negative externalities, creating markets is mainly used when managers cannot decide how external behavior responds to public policies, establishing property is mainly used when cost of bargain is low and external sources are very easily identified, regulation is generally low efficiency. But only public expenditure is used to correct positive externalities. At the same time, public expenditure can effectively complement insufficient supply of external behavior resulting from positive externalities. But Rosen (1995) also reminded us: public expenditure to correct positive externalities must carefully avoid waste. Shah (1995) proved Roson's view and affirmed public financial measures exist incentive effects on R\&D investment of private enterprises.

Lichtenberg (1987) had also proved public research expenditure has an important influence on R\&D input of private enterprises. Lach (2002) analyzed manufacturing empirical data of Israel in the 1990s and found government public expenditure greatly stimulates the small enterprises' innovation behavior, but not very significant to large enterprises. He pointed out that one unit government expenditure can stimulate eleven units innovation input of small enterprises, but only 0.23 unit for large enterprises because public expenditure generally flows into large enterprises.

In China, innovation independently and government public expenditure used to stimulating innovation independently are low-efficiency. There is a big gap in field of independent intellectual property between China and major industrialized countries. In 2007, China's three kinds of patents(inventions, utility models and designs) granted accounted for about $3 \%$ in the world, but Japan was $42.12 \%$, America was $19.36 \%$, South Korea was $8.72 \%$ and Germany was $8.10 \%$. And in this year, China's R\&D input was also insufficient comparatively. In 2006, China's R\&D expenditure accounted for $1.42 \%$ in GDP, but Japan was $3.39 \%$, South Korea was 3.23\%. America was $2.62 \%$ and Germany was $2.53 \%$. Therefore, input of R\&D funds in newly-industrialized countries and western developed countries is much higher than China.

In 2008, the top five regions of three kinds of patents(inventions, utility models and designs) granted in China (including Hong Kong, Macao and Taiwan) were Guangdong, Zhejiang, Jiangsu, Shandong and Shanghai, the corresponding proportions were $17.6 \%, 15.1 \%, 12.6 \%, 7.6 \%$ and $6.9 \%$. But Inner Mongolia was $0.38 \%$, its ranking was No.28. In the same year, in large and medium-sized industrial enterprises by area (excluding Hong Kong, Macao and Taiwan), the top five regions of the proportion of R\&D funds in GDP were Guangdong $(0.137 \%)$, Jiangsu $(0.136 \%)$, Shandong $(0.115 \%)$, Zhejiang $(0.064 \%)$ and Shanghai $(0.060 \%)$. But Inner Mongolia was $0.009 \%$, its ranking was No.21. This shows that innovation independently and public expenditure used to stimulating innovation independently are also low-efficiency in Inner Mongolia.

Based on above description, we study necessarily the relationship between innovation independently and public expenditure in Inner Mongolia and further find out the optimal level of public expenditure stimulating innovation independently efficiently. Therefore, this paper will use empirical data in Inner Mongolia to solve the optimal level of public expenditure and provide some corresponding suggestions. 


\section{Testing the empirical data of Inner Mongolia}

The data in this paper all come from International Statistical Yearbook, China Statistical Yearbook, Inner Mongolia Statistical Yearbook, China Statistical Yearbook on science and technology and Science and Technology Agency of Inner Mongolia. By testing these data, this paper will want to find a result about the relationship between innovation independently and government expenditure incentive in Inner Mongolia.

\subsection{The causality between innovation independently and incentive of public expenditure behavior}

To study the causality between innovation independently and incentive of public expenditure from micro-level, first, we observe statically from micro-level relationship between public expenditure of research \& development (R\&D) supported by government and its output. Because R\&D organizations such as colleges and universities, research institutions etc. are characteristic of patents, with taking effectiveness of patents into account, we regard three kinds of patents (inventions, utility models and designs) granted not applications as the indicator of R\&D output and intramural expenditures on science and technology activities (it is defined as actual expenditures for science and technology activities in reporting year, it reflects the actual performance of science and technology inputs) as the indicator of public expenditure. Samples are selected from 2000 to 2008. GI means government public expenditure, that is, government incentives. II means patents granted, that is, innovation independently. Their relationship is shown in Figure 1.

\section{$<$ Figure 1 about here $>$}

From Figure 1, we have the results: with the growth of public expenditure, innovation independently also enhances, with innovation independently enhancing, public expenditure also increases. But we are not sure to come to this result: there is a significant causality between public expenditure incentive and innovation independently in Inner Mongolia. Thus, we also need to do Granger Causality Tests, its result is shown in Table 1.

\section{$<$ Table 1 about here $>$}

Table 1 is the result of lag one period, because China is in pursuit of higher efficiency (related research indicated that the lag period of applied research is usually two years). The result above is that we expect:

-On the one hand, the probability of "innovation independently does not Granger Cause public expenditure" is almost zero and this conclusion is significant.

-On the other hand, the probability of "public expenditure does not Granger Cause innovation independently" is also almost zero and this conclusion is also significant.

In other words, Inner Mongolia government's public expenditure indeed greatly has stimulated innovation independently behavior and the momentum of innovation independently also has effectively attracted Inner Mongolia government's strong support through the way of providing public expenditure. It means that public expenditure incentive and innovation independently can promote each other. This is so-called "Matthew Effect".

\subsection{The impulse response between public expenditure incentive and innovation independently}

To further examine the impact effect of public expenditure and innovation independently, we need to build a distributed lag dynamic econometric model to observe the response of innovation independently behavior to public expenditure incentive and study the strength of government incentive. Samples are also selected from 2000 to 2008. So the Vector Auto-regression Model (VAR) composed by two variables of innovation independently and public expenditure is:

$$
\left[\begin{array}{l}
I I \\
G I
\end{array}\right]_{t}=\left[\begin{array}{cc}
-0.335681 & -0.000955 \\
400.3196 & 0.501358
\end{array}\right]\left[\begin{array}{c}
I I \\
G I
\end{array}\right]_{t-1}+\left[\begin{array}{cc}
-0.620029 & 0.004050 \\
79.46933 & 0.387511
\end{array}\right]\left[\begin{array}{c}
I I \\
G I
\end{array}\right]_{t-2}+\left[\begin{array}{c}
1132.614 \\
-277783 \\
.2
\end{array}\right]+\left[\begin{array}{l}
\hat{\varepsilon}_{0} \\
\hat{\varepsilon}_{1}
\end{array}\right]_{t}
$$

After stability test, we gives the dynamic response of related impact about public expenditure and innovation independently, and we have the figure of impulse response function as shown in Figure 2.

$<$ Figure 2 about here $>$

By Figure 2, we come to two conclusions:

(1) In the beginning, the response of innovation independently to public expenditure incentive is negative and lowest in the second period. After that, this response begins to rise and becomes positive and appears positive growth, but this positive response is fluctuant. In other words, public expenditure incentive on innovation independently is unstable, the scale of incentive is not optimal.

(2) The response of public expenditure incentive to innovation independently is negative from the first period to the later period of the first. After that, the positive response slowly appears. However, this positive response starts to fall. Overall, this response is not very clear. 
To more clearly study the response of innovation independently to public expenditure incentive, we give variance decomposition (as shown in Table 2) about innovation independently based on VAR to further observe dynamic characteristics about public expenditure stimulating innovation independently.

$<$ Table 2 about here $>$

From Table 2, we can learn that innovation independently is caused by itself, that is, even without financial incentive, enterprises' technological innovation behavior does not stop, and this innovation behavior is a spontaneous act. The contribution from itself has remained above $80 \%$ in all four periods and the contribution from public expenditure incentive has remained below $20 \%$. But we can find the contribution of innovation independently from itself is getting lower and lower, which means this spontaneous act is getting weaker and weaker and the contribution of external incentive gradually is getting stronger and stronger.

The contribution of innovation independently from itself goes down to $84.3385 \%$ in the fourth period from $100 \%$ in the first period. The contribution of public expenditure to innovation independently goes up to $15.6615 \%$ in the fourth period from $0 \%$ in the first period, of which this contribution goes down to $15.6615 \%$ in the fourth period from $19.6914 \%$ in the third period, which means this contribution is fluctuant though it is a upward trend overall. This shows the scale of public expenditure is not appropriate, so it is difficult to ensure the steady growth of innovation independently. Thus, it is essential to find the optimal scale of public expenditure to stimulate innovation independently of Inner Mongolia.

\subsection{The scale of expenditure on $R \& D$ in twelve areas (their scales are all above 1\%) in China}

$<$ Table 3 about here $>$

Table 3 shows that the mean of scale of expenditure on R\&D (Note 1) in twelve areas is about $1.939 \%$, so we can estimate: the optimal scale of expenditure on R\&D stimulating innovation independently is $1.939 \%$. But the scale is only $0.397 \%$ in Inner Mongolia, this number is equivalent to $20.4 \%$ of the optimal scale, less than half.

Those areas shown in Table 3 have higher expenditure on R\&D, which can effectively stimulate their innovation independently behavior and make their economic strength and competitiveness hold the leading position. The supportive scale in Beijing, Shanghai, Tianjin and Guangdong is much higher because they are capital, special economic zone or port and they have convenient transportation and higher degree of openness. The scale of expenditure on R\&D in Beijing has maintained the leading position, which greatly guarantees its strong innovation behavior and competitiveness as the capital and play an important role in driving innovation independently behavior in other regions in China.

\section{Conclusions and corresponding suggestions}

\subsection{Conclusions}

This paper has tried to find the relationship between public expenditure and innovation independently and has made a empirical test using data from Inner Mongolia. However, the empirical analysis has existed some shortcomings yet, i.e. how to quantify indicators, errors when processing data, inadequate samples and so on but author draws some helpful conclusions from analysis above text:

(1) From Figure 1, Granger causality tests and variance decomposition, we know that public expenditure effectively has stimulated innovation independently behavior and the momentum of innovation independently behavior also has promoted public expenditure incentive, that is, public expenditure and innovation independently can promote each other. Innovation independently behavior is mainly caused by itself, the contribution of public expenditure incentive to innovation independently is less than $20 \%$, but this contribution has been getting stronger and stronger.

(2) The optimal scale of expenditure on R\&D stimulating innovation independently is about $1.939 \%$, but the scale in Inner Mongolia is equivalent to $20.4 \%$ of the optimal scale. A good thing is: the scale of expenditure on R\&D stimulating innovation independently in Inner Mongolia is gradually approaching to the optimal scale.

(3) Inner Mongolia Autonomous Region must gradually increase expenditure on R\&D to effectively stimulate its innovation independently behavior and improve its regional competitiveness.

\subsection{Corresponding suggestions}

Author's four suggestions as following:

(1) Increasing Inner Mongolia government's financial inputs to effectively stimulate its innovation independently behavior. The Ministry of Finance in Inner Mongolia must guarantee statutory growth requirements in budget in the beginning of the year and try its best to approach to the optimal scale of expenditure on R\&D. 
(2) China's government is ready to further strengthen financial inputs on the basis of "the Eleventh Five Year Plan", so Inner Mongolia government also increases its financial inputs to ensure the growth of input on $R \& D$ funds is higher than the growth of recurrent revenue. At the same time, Inner Mongolia government must continue to optimize the investment structure and reasonably allocate investment resources and further improve the basic conditions for scientific research to enhance overall scientific research capacity. In addition, public expenditure also specially provides essential and adequate financial inputs to basic research, applied research, cutting-edge scientific \& technological research and major or important scientific research project of nation or Inner Mongolia.

(3) To better the work of funds management and improve the usage of funds, which plays an important role, too. The Ministry of Finance in Inner Mongolia should reasonably cooperate with other relevant departments to make better management style to strengthen and improve usage of scientific research funds together.

(4) To establish Performance Evaluation System of public expenditure incentive to innovation independently and continue to explore the laws of science and technology activities. Besides, to set up a convenient and effective management mode to achieve the optimal scale of public expenditure to better stimulate innovation independently in Inner Mongolia.

\section{References}

Cropper, M. L. \& Oates, W. E. (1992). Environmental economics: a survey. Journal of Economic Literature, 30.

Delong, J. B. \& Summers, L. H. (1991). Equipment investment and economic growth. Quarterly Journal of Economics, 106(2).

Fan, Huanhuan \& Zhang, Lingyun (2009). EViews: Statistical Analysis and Application. Beijing: China Machine Press. (in Chinese)

Lach, S. (2002). Do R\&D subsidies stimulate or displace private R\&D, evidence from israel. The Journal of Industrial Economics, 50.

Lichtenberg, F. R. (1987). The effect of government funding on private industrial research and development: a reassessment. Journal of Industrial Economics, 9.

Liu, Qiongzhi (2009). Economic Growth and Social Equity: Theoretical Model and Empirical Research of Financial Incentives. Wuhan: Wuhan University Press. (in Chinese)

Nadiri, M. I. (1993). Innovations and Technological Spillovers. Working Paper, 4423, Cambridge, MA: National Bureau of Economic Research, 8.

Nelson, R. R. \& Winter, S G (1982). The schumpeterian tradeoff revised. American Economic Review, 72.

Rosen, H. S. (1995). Public finance. McGraw-Hill.

Shah, A . (1995). Fiscal incentives for investment and innovation. The world Bank.

Wang, Yunfang \& Yue, Ying (2008). Research on Innovation Incentive Mechanism of Scientific and Technological

Enterprises. Beijing: China Social Science Press. (in Chinese)

\section{Notes}

Note 1 . The scale of expenditure on R\&D is the proportion of expenditure on R\&D in GDP.

Table 1. The Granger Causality Tests of public expenditure incentive and innovation independently

\begin{tabular}{|l|c|c|c|}
\hline \multicolumn{4}{|l|}{ Pairwise Granger Causality Tests } \\
\hline Sample: $2000-2008$ \\
\hline Lags: 1 & Obs & F-Statistic & Probability \\
\hline Null Hypothesis: & 8 & 10.7991 & 0.02180 \\
\hline II does not Granger Cause GI & & 10.5952 & 0.02257 \\
\hline GI does not Granger Cause II
\end{tabular}


Table 2 . The variance decomposition about innovation independently

\begin{tabular}{|c|c|c|}
\hline Period & II & GI \\
\hline 1 & 100.0000 & 0.000000 \\
\hline 2 & 92.03259 & 7.967410 \\
\hline 3 & 80.30860 & 19.69140 \\
\hline 4 & 84.33850 & 15.66150 \\
\hline Cholesky Ordering: II GI \\
\hline
\end{tabular}

Table 3. The scale of expenditure on R\&D in areas (their scales are all above 1\%) in China in 2007

\begin{tabular}{|c|c|c|c|}
\hline Areas & $\begin{array}{c}\text { The proportion of } \\
\text { expenditure on } \\
\text { R\&D in GDP }\end{array}$ & Areas & $\begin{array}{c}\text { The proportion of } \\
\text { expenditure on R\&D } \\
\text { in GDP }\end{array}$ \\
\hline Beijing & $5.403 \%$ & Zhejiang & $1.499 \%$ \\
\hline Shanghai & $2.522 \%$ & Sichuan & $1.324 \%$ \\
\hline Tianjin & $2.271 \%$ & Guangdong & $1.301 \%$ \\
\hline Shaanxi & $2.228 \%$ & Hubei & $1.206 \%$ \\
\hline Jiangsu & $1.671 \%$ & Shandong & $1.203 \%$ \\
\hline Liaoning & $1.500 \%$ & Chongqing & $1.140 \%$ \\
\hline
\end{tabular}

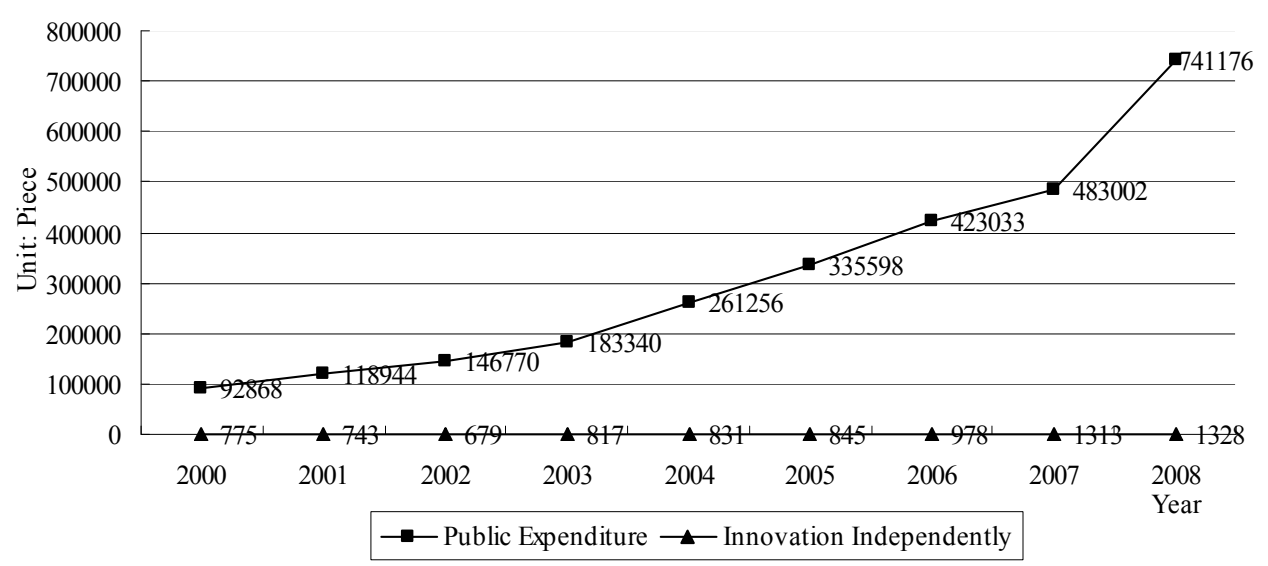

Figure 1. The Relationship between Public Expenditure and Innovation Independently
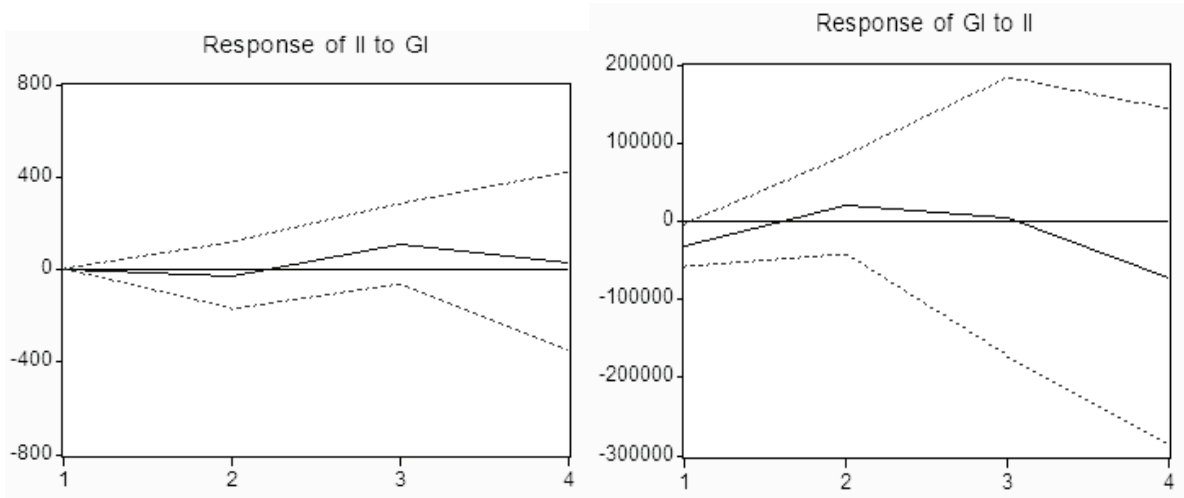

Figure 2. Response to Cholesky One S.D. Innovations \pm 2 S.E.

The dynamic response of related impact about public expenditure and innovation independently 